\title{
Coping Mechanisms of Caregivers of Persons Diagnosed With Severe Mental Illness in South Africa*
}

\author{
Lynne Hogan, Johannes John-Langba \\ University of Cape Town, Cape Town, South Africa
}

\begin{abstract}
This paper explores the coping mechanisms of caregivers of persons diagnosed with severe mental illness to gain a better understanding of caregivers' experiences and the barriers and challenges encountered in fulfilling their role as mental health caregivers in South Africa. The study utilised a qualitative research methodology to explore the coping mechanisms of caregivers of persons diagnosed with severe mental illness. Employing a purposive sampling technique, 18 in-depth interviews were conducted with caregivers of individuals diagnosed with severe mental illness in the Western Cape Province of South Africa. Findings show a wide range of both positive and negative coping mechanisms which caregivers employ in order to deal with the challenges and stresses they face. Positive coping mechanisms ranged from: making use of services and facilities available, working or keeping busy, knowledge of mental illness, support from family and friends, faith, finding the right doctor for the mentally ill person, support from hospital or clinic staff, looking after self and using challenges to grow, having lots of patience, taking one day at a time and listening to others' stories. Some of the negative coping mechanisms were: ignoring the mentally ill person or cutting off emotions, taking on all responsibility for the mentally ill person or controlling them, using verbal threats or abuse, isolating themselves and using medication to cope. Mental health care barriers that are considered external to the family unit are examined including recommendations on how to address the mental health needs of carers of persons with mental illness at the community level in South Africa.
\end{abstract}

Keywords: caregivers, coping mechanisms, mental health, severe mental illness

\section{Introduction}

There is global growth in the burden of mental illness in society, particularly in developing countries. In the year 2000, mental disorders comprised $12 \%$ of the global burden of disease and it is predicted that by the year 2020 this could increase to $15 \%$ (Flisher et al., 2007). According to the World Health Organization (WHO), a significant majority (77\%) of individuals admitted to mental hospitals are discharged within one year (WHO, 2011). This has been attributed to the global trend to deinstitutionalise the care of people diagnosed with a mental illness resulting in families or caregivers in the community tasked with the responsibility of caring for those who are diagnosed with a mental illness (Rudnick, 2004).

The responsibility of care causes many stresses and challenges for the person who is the primary caregiver

\footnotetext{
*Acknowledgements: The authors would like to thank the Executive Director and staff of Cape Mental health for their support as well as all the participants for their time and sharing invaluable insights about the mechaisms they use to cope with the burden of caring for persons diagnosed with severe mental illness.

Lynne Hogan, MSocSci (Clinical Social Work), Department of Social Development, University of Cape Town.

Johannes John-Langba, Ph.D., MPH., MSW., Department of Social Development, University of Cape Town.
} 
and the family involved with the care (Solomon \& Draine, 1995). There is an apparent global shift in the task of mental health caregiving from institutions to communities with an estimated $30 \%$ to $65 \%$ of people diagnosed with a mental illness live with their families worldwide (Solomon \& Draine, 1995). The result is that families or caring individuals in the community now have the responsibility of caring for those who are diagnosed with a mental illness (Rudnick, 2004). This responsibility of care causes many stresses and challenges for the person who is the primary caregiver and the family involved with the care (Solomon \& Draine, 1995). South Africa over the past few decades has also gone the route of deinstitutionalisation resulting in many mentally ill people living at home with families or in the homes of caring community members rather than in institutions. It is important therefore to support and consider those caring for the mentally ill so that they too can continue in good health and provide the much needed care for those diagnosed with a severe mental illness. Since the onset of deinstitutionalization, it has increasingly become the family and community's responsibility to take care of those diagnosed with a severe mental illness.

This has had an impact on both families and communities as the responsibility of care takes time, resources and often causes increased stress (Rudnick, 2004; Crowe \& Lyness, 2013; Seloilwe, 2006). Mental health care professionals are now required to work with these families and community members who are providing care as it is recognised that they are often the main resource and support system for many severely mentally ill people (Seloilwe, 2006; Romi \& Melamed, 2007). They carry a significant burden in their role as caregivers of the many mentally ill people living in our communities.

The caregivers' own mental health and general well-being have now become areas of concern for mental health care professionals (Ho, Collins, Davis, \& Doty, 2005; Solomon \& Draine, 1995). In this study, "caregivers" are those family or community members who take the primary responsibility for the psychological and physical well-being of the person diagnosed with a severe mental illness. They are individuals not employed to do so but who provide such care voluntarily. They may either live with the person who is severely mentally ill or live elsewhere but usually in close contact with that person.

For the purposes of this research, "severe or serious mental illness" includes major depression, schizophrenia, bipolar disorder, obsessive compulsive disorder (OCD), panic disorder, posttraumatic stress disorder (PTSD) and borderline personality disorder as diagnosable in the Diagnostic and Statistical Manual for Mental Disorders V. (American Psychiatric Association, 2015). "Coping mechanisms" refers to what a person does and thinks in response to an event or situation, thus dealing with events or situations with varying degrees of success (Huang, Sun, Yen, \& Fu, 2008). Coping mechanisms can be viewed as positive or negative, either improving a person's wellbeing or being harmful to a person's wellbeing (Costa et al., 1991). This paper therefore examines and identifies the key mechanisms used by caregivers to cope with the burden of caring for persons diagnosed with severe mental illness.

Prior researches on coping mechanisms in mental health have been conducted primarily in the context of life stress (Diehl, Chui, Hay, Lumley, Gruhn, \& Labouvie-Vief, 2014). Coping mechanisms are behavioural or cognitive responses made by any person contingent on a life event: thus coping is what a person does and thinks in response to an event, with varying degrees of success (Huang et al., 2008). This study hopes to highlight the variations in coping mechanisms used by caregivers in response to caring for family or community members who are severely mentally ill.

Huang et al. (2008) studied carers coping with those who suffer from schizophrenia in Taiwan and found that most carers were of low socio-economic status and low educational levels. This seemed to influence their 
coping mechanisms in that it delayed their seeking psychiatric help as they first went to traditional healers or tried Chinese medicine before going for psychiatric help (Huang et al., 2008). They also found that those from better educated classes would seek information about the illness and were members of support groups which helped them cope better (Huang et al., 2008).

Known coping mechanisms used by caregivers include: physical coping mechanisms which include caregivers using alcohol, smoking, medication, relaxation, sleeping, resting and overeating to help them cope; psychological coping mechanisms which include emotional (crying, denial, upset), cognitive (positive thinking, information, problem-solving) and behavioural (hobbies and action-orientated pursuits) responses; and finally, social coping mechanisms including social support, community resources, professional support, spiritual support, respite care and group/ self-help groups (Huang et al., 2008).

Research in this area is very scarce in South Africa. A thesis was done in 2002: "An exploratory study on the needs of families with a relative with schizophrenia who are utilising services at Cape Mental Health Society (located in Cape Town)", by Paula Sellmeyer, investigated the needs rather than the coping mechanisms of families. But the researcher hasn't yet found an exploratory study on the coping mechanisms caregivers in Cape Town (or South Africa) use when caring for a severely mentally ill family or community member (Sellmeyer, 2003).

Some research has been done around the fact that different family members interpret mental illness in a variety of ways and thus respond differently (Johnson, 2000). However, little attention has been given to how spouses cope (Johnson, 2000). In Huang et al.'s (2008) study often the first coping mechanism used by the predominantly low socio-economic sample involved traditional healers, shamans and traditional herbal medicine. There is a large section of our population in South Africa that also make use of traditional medicine and healers when it comes to caring for those with a severe mental illness.

It has also been found that the family and caregivers of persons with a severe mental illness can affect the outcome of the illness and relapse rates, so it is important to consider how that person or family unit cope (Rudnick, 2004). Helping the caregiver cope and finding which support systems and coping mechanisms help caregivers, will not only improve family functioning and promote caregiver well-being but will ultimately help the person suffering from a severe mental illness (Crowe \& Lyness, 2014).

Understanding the coping mechanisms caregivers use when caring for a person with a severe mental illness diagnosis, will guide and inform best practice. A plethora of research has highlighted the importance of caregivers to the well-being and relapse rate of persons diagnosed with a severe mental illness (Romi \& Melamed, 2007; Crowe \& Lyness, 2013; Bland \& Foster, 2012; Johnson, 2000; Solomon \& Draine, 1995; Williams et al., 2014). Although various other research have highlighted the importance of providing relevant and evidence-based interventions to support the psychosocial wellbeing of caregivers of persons diagnosed with severe mental illness (Ho et al., 2005), there is however a dearth in research in South Africa on how caregivers cope with caregiving burden notwithstanding the growing number of caregivers, resulting from deinstitutionalisation of mental health care.

Grounded on both stress and coping theory (Lazarus, 1993) and resilience theory (Green, 2002), this paper explores the coping mechanisms of caregivers of persons diagnosed with severe mental illness in South Africa. Stress and coping theory posits that in order to establish coping mechanisms it must first be established how the person has appraised a situation or transaction; have they judged it as irrelevant, benign-positive or stressful? (Lazarus, 1993; Eisdorfer, 1981). Resilience theory posits that challenges and difficulties individuals and 
families face during the course of a lifetime are part of the human experience. These vary from daily difficulties to traumas which the human psyche is forced to deal with. Some individuals appear to be able to handle (even thrive on) these difficulties and traumas while others are too overwhelmed to cope and are affected adversely (Fletcher \& Sarkar, 2013; Van Breda, 2001; Greene, Galambos, \& Lee, 2003). An individual's resiliency is determined by the interaction of risk and protective factors (Greene et al., 2003; Van Breda, 2001). Resilience theory assumes that resilience is one way in which individuals overcome the adversities they experience in their lifetime and even become stronger, healthier people (Van Breda, 2001; Fletcher \& Sarkar, 2013; Windall \& Bennet, 2012).

\section{Method}

A qualitative research design that utilized a social constructionist epistemology was employed to explore the coping mechanisms of caregivers of persons diagnosed with severe mental illness. The population included persons attending a support group for caregivers of persons diagnosed with severe mental illness in Cape Town, South Africa. Using both purposive and snowball sampling methods a total of 18 participants were recruited from one support group hosted by a mental health service organization in Cape Town. They were all female participants caring for a mental ill family member that is living with them in the same household or outside their household with 13 of the caregivers interviewed were living in the same household with the mentally ill person and five lived elsewhere in the community. The inclusion criteria were that participants should be a caregiver of a person diagnosed with severe mental illness as well as attending a caregiver support group in Cape Town.

In-depth interviews (IDI) using a semi-structure IDI schedule including questions that explored the coping mechanisms related to the stress and burden of providing care to a person diagnosed with severe mental illness. The elicited interviews were conducted in the preferred language of the participant and recorded with their consent. The recorded data was transcribed and analyzed using Tesch's thematic approach to qualitative data analysis (Tesch, 1990). The findings were verified for trustworthiness including credibility, transferability, dependability and confirmability (Lietz, Langer, \& Furman, 2006). Ethical approval was obtained from the University of Cape Town's Ethics in Research Committee as well as from the mental health service organization where participants were recruited. Because human participants were interviewed for this research all the necessary approvals were obtained from the University of the Cape Town and Cape Mental Health where participants were recruited.

\section{Limitations}

Participants in this study were those caregivers that were proficient in either English and/or Afrikaans. These criteria seemingly excluded those caregivers not proficient in the aforementioned languages and were therefore not recruited to participate in the study. Another limitation was that the majority of participants were either White or Coloured. Only three of the 18 participants were black, thus the participants selected may not be representative of the socio-demographic characteristics of the South Africa population and society. In addition, all participants were female and thus male caregivers were not represented; therefore findings cannot be generalised across both genders. The sample in this study was limited to participants who were willing and available to participate on a completely voluntary basis during the time set aside for data collection by the researcher. The participants were also mostly from Cape Mental Health or the Cape Support for Mental Health which also limits the generalisation of the findings to all caregivers. 


\section{Results}

Findings show that carers of persons diagnosed with severe mental illness face many challengers and stresses in their caring role. They utilised various methods of coping; some methods were healthy and appropriate while others were inappropriate and caused more strain in the already strained situation in which they found themselves.

The positive coping mechanisms included: making use of services and facilities available, working or keeping busy, knowledge of mental illness, support from family and friends, faith, finding the right doctor for the mentally ill person, support from hospital or clinic staff, looking after self and using challenges to grow, having lots of patience, taking one day at a time and listening to others' stories. Some of the negative coping mechanisms were: ignoring the mentally ill person or cutting off emotions, taking on all responsibility for the mentally ill person or controlling them, using verbal threats or abuse, isolating themselves and using medication to cope.

\section{Use of Available Services and Facilities}

The majority of participants used available services and facilities as a coping mechanism. These included 12 participants attending support groups and almost all making use of clinics/hospitals or mental health services of some kind. It seemed that those attending the support groups coped better and were more able to resolve difficulties than those who didn't. It was also evident that those carers who were better educated and in middle to high socio-economic group were able to make use of more services and facilities and sought them out proactively.

A 72 year old mother put it this way:

I started going to a support group... I spoke to other people in the support group and most of them had been through this and survived it... it does help without a doubt.

Another said:

I have no one to offload on except the support group and the psychiatrist. —64 years old mother

A 60 year old mother said the following when asked what helped her cope:

It was joining the support group which was probably the absolute best thing that happened because that's how I learnt, that's how I could speak to other people. I got onto the committee and I've probably been the chairperson for a long time - at least 12 years I think... the support group has been helpful because you can speak out and encourage other people to speak out and to understand the illness and things like that... a sense of giving back. That to me made a big difference.

It seemed that most participants felt their experience could only be truly understood by those who experienced the same thing and had an understanding of what they were going through. This was of great supportive value and gave them encouragement.

\section{Working and Trying to Be Busy}

Many participants also indicated that working or keeping busy by being involved in hobbies or other activities was of great value as a coping mechanism. This seemed to take their mind off the immediate problems and stress of caring which they may be dealing with and allowed them to cope better.

One mother of 70 years (now retired) put it this way:

I did work all along and that kept me busy and I think it helped. It helped take your mind off things that were happening. 
Another mother of 59 years said:

And then I've got my work. I do work also a little bit... so I've got a nice balance so they know nothing. I don't talk to them at all about that (son's illness). We've gota good working relationship that helps me.

And:

I work mornings only. I realised I can do this, I must get out. I also need to do things for myself. $— 56$ years old mother

Other carers who didn't have work expressed that keeping busy at home or being involved in activities outside of the home was also a good way to help cope.

I am fixing up my house and I have to keep it up... I try find things to do to occupy my time and mind. — 64 years old mother of daughter with schizoaffective disorder

This sense of being busy and doing something outside of caring seemed to give the carers a better sense of well-being and the ability to cope better than those not working or busy.

\section{Knowledge and Understanding of the Diagnosis}

Those carers who took time and energy to find out about the person's illness and what to expect seemed to cope far better than those who were uninformed and perhaps unwilling to accept the person's mental illness diagnosis. For instance:

I educated myself enormously. Learning as much as possible (about the mental illness) makes all the difference. -60 years old mother

Another mother of 70 years said:

You will read anything and research anything you find, any sort of answer. It becomes your mission. Somewhere out there they might have or say something that is different, it is interesting, and it is helpful.

Those carers who understood the person's mental illness and were aware of what to expect seemed to cope better in general.

One mother of 72 years whose son is now married and living independently reported coping better because:

I read all I could. I spoke to all I could. So I informed myself as much as I could.

\section{Support from Family and Friends}

The support and help from friends and family was a significant coping mechanism for carers. Carers were able to cope much better by talking to and sharing problems with family and friends. The sister of a person diagnosed with several mental illnesses responds as follows:

Interviewer: Who can you go to, to ask for help, if you need help coping with her?

Participant: I would be able to get help. No, I've got big support of my family and friends. I have a big support system. What helps me cope is that I've got help. — caregiver aged 59 years

Another quote was:

I've been open with my friends from the very start. I never hid it. And so my friends from the beginning, have always been incredibly supportive. When I need to talk to anybody there are people I can talk to. - mother of 60 years old 
Fourteen out of the eighteen participants expressed that support of family and friends made a significant difference to their ability to cope. They were able to share their difficulties and stresses in caring for the mentally ill person, as evidenced by the following:

Interviewer: And your husband?

Participant: He is wonderful and a great help. He is not so emotionally charged and can stand back and look at the situation and calm me if I am anxious about her (their daughter). — mother aged 56 years

\section{Faith and Religiosity}

Almost half of the carers interviewed spoke openly about how their faith has given them strength to cope and a feeling that they have help from a higher power as evidenced in the following quotes:

Who looks after me? God looks after me. -59 years old sister caring for her brother

Another carer when asked what helps her cope said:

My faith, I have a very strong faith and am so thankful I can rely on Jesus to help me each day. — 63 years old wife of husband with bipolar disorder

The ability to connect with a higher power seems to give carers strength and support which carries them in their role as carers.

\section{Finding the Right Doctor for the Mentally III Person}

Many carers spoke openly about how finding a doctor who they could speak to honestly about the person they were caring for and who included them as part of a team in helping the mentally ill person, made it a lot easier to cope. They felt heard and supported in their role as carers.

For example, one mother said:

There's the family and there's the medical people and things will only work if they work together... I feel very strongly that it is a team. If someone doesn't want to hear what's going on at home-find another doctor. 'Cause things won't get better unless someone (doctor) is going to listen and work with the family and respect the family. — 60 years old mother of a son with schizophrenia

A number of participants said the doctors and medical staff made them feel that they were part of their family member's mental illness problem. They were excluded from any treatment plan, which made them feel helpless and confused. Once they found a different doctor everything changed and they were better able to cope. One mother put her initial experience with doctors this way:

They think I'm being overbearing and want to know about everything. But with the person's permission there must be things they can discuss to help the person... I found the people at J2 (Groote Schuur Hospital) a huge support. I managed to find someone there who worked out for her. I try connecting with her Dr. It's so positive and I don't know how it will be in the future but it's good now. - mother of 56 years old

\section{Support from Hospital or Clinic Staff}

Many carers said that getting support and the right kind of help from the hospital or clinic for the mentally ill person made a big difference to their ability to cope. Those who had a positive experience at hospitals or clinics were in a better position to cope with the person who was mentally ill, as expressed in the following quote:

I found the people at J2 (Groote Schuur Hospital) a huge support, they are interested and have helped her (daughter). 
-56 years old mother

Another participant whose brother collects medication from a local clinic reports:

They talk, they tell me about him, how he must drinks his tablets. How in the morning when I drink mine but he doesn't because he is sleeping too late... no, they help him. -71 years old sister

\section{Looking After Self and Using Challenges to Grow}

Two coping mechanisms which appeared to be closely linked were the carers' ability to continue doing things which nurtured themselves and looking at the challenges they faced in order to grow and develop as people. Two participants across different population groups explain their experience as:

Participant 1: I also need to go do things for myself and let her do it. I think I've been able to see the challenges and used them to actually grow in my life... So I've used the things to help me look at life differently and not be so inflexible.

Participant 2: I do think you've got to have your own interests. But I mean, it pushed me into areas that I would never have gone. I came onto the committee (of support group), I did public speaking - all things I found stressful. You become quite knowledgeable. I mean we wrote a book!! —56 and 70 years old mothers

The ex-wife of a person who was diagnosed with bipolar disorder did the following:

To be alone, I just recharge my batteries. I have a lovely little dog which I take for walks. And I eat very well... Meditation. I go for therapy. Sleep, can I say sleep? I go to bed early... I address things. I don't have a bottle of wine at night, even tho' it's painful. —54 years old ex-wife

\section{Having Lots of Patience}

Nearly half the carers interviewed told the interviewer that they have lots of patience which makes the caring role more manageable, as evidenced through the following quote:

You have to be patient even if you are angry sometimes you've got to adjust yourself and then you think oh no, that's happening. And then you know how to carry on. -59 years old sister

Some of the participants reported that this was a skill they had to develop while others said that fortunately they were by nature patient people.

A 56 year old mother put it this way:

Often I said things that weren't helpful and I've had to learn to step back and be careful.

\section{Taking it One Day at a Time/ living in the Now}

An effective coping mechanism for seven out of the 18 participants was taking one day at a time. Living in the now and not worrying about the future or making plans for the future which may just add to the stress of getting through each day.

When asked by the interviewer, "What are the ways which you find/feel help you cope?", this is how two mothers responded:

You can only take one day at a time. - 66 years old mother

...I was so worried about the future. You do learn to live differently and you learn to take one day at a time, a stress at a time and it's so true. It's the only way to go. -60 years old mother

It became clear during the interviews that those carers who could take one day at a time were more able to cope with the stresses caring brings. 


\section{Listening to the Stories of Other Caregivers}

This was such an interesting coping mechanism which the interviewer came across in a third of participants in the study. Those carers who were able to listen to others' stories of adversity, even if not from others in the same situation, seemed to draw strength and encouragement for their own situations. Naturally the support groups were the primary place for this to happen and those who were engaged in helping others' carers. But a couple of participants found it helpful to listen to the stories of any others.

The wife of a husband with bipolar disorder said she didn't attend any groups for the support of mental illness carers but found it helpful going to AA. She said what helped her was:

Real stories. I was fascinated by their stories not only of staying sober but of their actual behaviour while they were alcoholics and the family support... For 2 years I used to go. -63 years old wife

Some participants did however also use negative coping mechanisms which were not particularly helpful in dealing with their situation in the longterm. Some of these were not generally good for their well-being but were employed as an immediate way to cope in reaction to stressful situations they found themselves in. Some of the negative coping mechanisms included: Ignoring the person or cutting off emotions, taking on all the responsibilities for the mentally ill person or controlling them, using verbal threats or abuse, isolating themselves and using medication to cope.

\section{Ignoring the Mentally IIl Person or Cutting off Emotions}

Many participants in the face of ongoing stress in their role as carers found that in order to cope they would just ignore the person or cut off emotional responses to the person. This is detrimental to their well-being and even though it helped them cope in the short term it caused emotional problems for them and those they are caring for in the longterm.

One carer reported that:

....when he was psychotic I used to have to learn to walk away. Learn not to respond even if there are... bizarre things. -60 years old mother

Another participant said:

Sometimes at home when he starts really going off on a tangent, then I just go to my room. I just close it (the door). -66 years old mother

\section{Taking on All Responsibilities for the Mentally IIl Person or Controlling Them}

An overwhelming majority of the carers took on almost all the responsibilities for the mentally ill person's well-being. It was evident that in the early stages of the illness this was much more prevalent, e.g., in the first five years. After that some carers would have learnt to seek help from elsewhere or encouraged the mentally ill person to take back some of the responsibilities for themselves. However other carers took control of the situation and the mentally ill person as a way of coping. The responsibilities that a caregiver has are overwhelming at times, depending on how ill or well the person they are caring for is, as evidenced by the following quotes:

I've had to develop a sense of almost responsibility that I thought would have left a bit by now... It's almost like you are still caring for a baby... You prepare yourself as a mother for every stage. And I hadn't prepared myself for this stage. I thought that then (by now) I would have more freedom. -59 years old mother

Because you know when they are ill they become again very dependant, like children... people would intimate that I was controlling him. -72 years old mother 
A sister aged 59 who cares for her sister put it this way;

When... was staying here last year I could control her to a certain extent because she was on medication and under my care. I suppose I've always felt emotionally responsible for her...it's...*sighs* always it doesn't go away.

The feelings and practicalities of being responsible for the person and trying to control things is a huge burden which carers have to live with.

\section{Using Verbal Threats or Abuse}

A few carers were open enough to speak about how they verbally threaten or abuse (verbally and physically) those in their care in order to cope. The stress of the caring role pushes some people into behaving in ways they would not typically behave. This situation is not healthy for the caregiver or the person with a mental illness, as described in the following quotes:

I need intervention. Because the way I'm... You know, I become... And I do shout, shout and I sometimes do swear. And he's going to have me up for abuse. - 66 years old mother

If he doesn't listen you know what I say? I think he is scared of my big sister... then I say "You know what? I am going to call Sheila (big sister), then you won't do this kind of thing". — 48 years old sister

These negative coping mechanisms are used when caregivers feel stressed and are struggling to deal with the person they are caring for.

\section{Going into Isolation}

Caregivers who felt overwhelmed and stressed by the demands of coping often isolated themselves as a coping mechanism. They had no energy to socialise or interact with others so they withdrew. This is evidenced through the following quotes:

No I don't have friends. It's only the street people. Ladies, they help me when he's wrong like that time... when I'm not feeling right, or stressing, I just go and sleep. — 71 years old mother of son diagnosed with schizophrenia

So what I would do is, I wouldn't invite people round, I don't want to upset her but then I would get to a point when I think, no hang on a second... - 59 years old sister

It seems that these coping mechanisms can lead to the caregiver feeling less able to cope and can make their caring role far more stressful in the long run.

\section{Using Medication to Cope}

Only three participants openly admitted they used medication to cope. However this coping mechanism may be more widespread than reported in this study, and may include the taking of other substances such as alcohol or drugs. One mother explained her experience:

I take pills. I told the chemist, I can't sleep, I've got 3 children... just give me something to calm me. — 52 years old mother

Another said the following:

Interviewer: If you need help coping, are there people you feel you can go to?

Participant: I've got a big support system... Oh yes, ya and I can go to my Dr and get happy pills when I need them.

\section{Discussion}

The findings in this research study show that caregivers experience huge stress and have to cope with many challenges in their role as carers resulting in them employing a range of coping mechanisms. They also 
encounter a number of barriers that render their task as caregivers even more difficult.

The fact that all of the participants were female and the majority was over 50 years old is consistent with previous studies (Ho et al., 2005; Seloilwe, 2006; Solomon \& Draine, 1995). All the caregivers in this study cared for a family member diagnosed with either schizophrenia, bipolar disorder and/or schizoaffective disorder.

A number of coping mechanisms which carers use are: making use of services and facilities available, working or keeping busy, taking time out for themselves, listening to others' experiences, educating themselves about the illness, relying on family and friends, using the challenges to grow and taking one day at a time. Some of the negative coping mechanisms were: taking complete control of the situation, ignoring the person, verbal or physical abuse, isolating themselves, using medication.

The most common coping mechanisms used by carergivers was making use of services and facilities available to them, especially attending support groups. This was particularly true for those who were better educated and from middle to upper socio-economic groups. This finding is consistent with the study done by Huang et al. (2008), which also found carers from better educated classes would seek information about mental illness and join support groups. The use of services and facilities include a variety of options from finding the right doctor for the person they are caring for, talking to helpful staff at facilities, to attending groups.

Social supports were as significant mediating factors in helping carers cope in their caregiving role. Both informal social support — such as friends and family, faith or religious affiliations and listening to other people's stories - and formal social support—such as groups and help from mental health care professionals - played a significant role in the carers' ability to cope. These findings were also consistent with those of Huang et al. (2008) and Solomon and Draine (1995), where use of social support is shown to be an effective coping mechanism.

The physical and behavioural coping mechanisms of keeping busy, using medication and taking time out for themselves were also mechanisms consistent with Huang et al.'s (2008) study where they found these to be common coping mechanisms. Cognitive coping mechanisms which that study and this one also have in common are positive thinking (using challenges to grow) and information seeking. Psychological coping mechanisms such as denial were evident in this study but not significantly; more significant was the evidence that taking one day at a time and being patient helped carers cope in their caring role.

Those caregivers who used more control in the relationship and had intense emotional reactions such as cutting off emotions or resorting to verbal abuse were those who were not coping as well as the others. This is also consistent with finding in studies done by Huang et al. (2008) and Solomon and Daine (1995), where it was evident that reactions with an emotional focus were not effective coping mechanisms. Two other negative coping mechanisms which were fairly common were ignoring the mentally ill person and the caregivers isolating themselves. These findings will add to the body of knowledge of caregiver coping mechanisms.

In the study, only three carers admitted to taking medication in order to help them cope. This number could be more as not all participants may have felt comfortable enough to share such information; this links with the study done by Huang et al. (2008) and Maglianio et al. (1998) where they found carers used a variety of substances to help them cope.

One coping mechanism which Huang et al. (2008) found in their study was how many carers from low socio-economic groups took those they cared for to traditional healers first before going for psychiatric help. In this study only one of the three black carers who came from a traditional low socio-economic background 
utilised this coping mechanism. However, this may be more prevalent and further research should be done in this area.

Also worth noting in this study are the coping mechanisms of ignoring the person who is mentally ill and the carers isolating themselves, which were reported by carers who found themselves struggling to cope. There is a gap in the literature around coping mechanisms positive and negative, in the South African context. These findings therefore add to the body of knowledge in this area and can help improve mental health care professionals' awareness in their work with carers.

The process of caregivers looking after mentally ill family members can be viewed from a resilience theory perspective. Most carers experience disruptions on and off when caring for a mentally ill person; they have to adapt and adjust over time and if this is done successfully they manage to adapt positively using positive coping mechanisms (Fletcher \& Sarkar, 2013). In this study this was evident in carers' use of coping mechanisms such as: making use of services and facilities available, working or keeping busy, knowledge of mental illness, support from family and friends, faith, finding the right doctor for the mentally ill person, support from hospital or clinic staff, looking after self and using challenges to grow, having lots of patience, taking one day at a time, listening to others' stories. These carers were able to overcome and handle the difficulties they faced, showing resilience as put forward by Fletcher and Sarkar (2013), Greene et al. (2003), and Van Breda (2001).

Caregivers who were not coping tended to use negative coping mechanisms, leading to lower level functioning. They used destructive behaviours which in this study were: ignoring the mentally ill person or cutting off emotions, taking on all responsibility for the mentally ill person or controlling them, using verbal threats or abuse, isolating themselves and using medication to cope. These findings are consistent with the resilience theory put forward by Richardson and colleagues as outlined in Fletcher and Sarkar (2013), where both adversity and positive adaptation indicate resilience. These findings link to the stress and coping theory proposed by Lazarus (1993) where the way in which a person appraised a situation would depend on how they coped with the situation. In this study, carers whose primary appraisal led to coping by information seeking and direct action, tended to cope better; while those who did not felt incapacitated and more stressed trying to cope. These findings link to studies done by Huang et al. (2007), Rudnick (2004), and Johnson (2000) which connect perceived burden and stress to modes of coping.

\section{Conclusion}

This research highlighted the many coping mechanisms caregivers use in their role as carers and the challenges they face. What was of particular interest was the important role social support plays in the carers' ability to cope and in the way they frame their situation. Those who connected with social support systems were coping better with their situation than those were remained isolated. It was also clear that those carers who were in contact with social support systems used more positive coping mechanisms and felt they had support in their caring role. Those carers from poorer socio-economic communities seemed less able to connect with social support systems, used more negative coping mechanisms and seemed to struggle more with caring. Such caregivers are in need of a variety of formal systems which provide healthcare and social support to both the person in need of care and the caregiver. The role Cape Mental Health and local clinics play in these poorer communities is very valuable and helpful to carers, however, there is a serious lack of services to support carers themselves. 
Overall, caregivers face many challenges and the stress of caring for a mentally ill person is often overwhelming. The challenges and stress carers face makes it harder for them to cope. Further research into the carer's own health, both physical and psychological, is needed in order to provide essential services for their well-being. A growing body of evidence shows that these caregivers play a crucial role in the mentally ill person's general well-being, functional independence and relapse rate (Williams et al., 2014) — thus looking after caregivers is essential. The evidence that carers are more likely than non-carers to have health problems has started to be reported (Ho et al., 2005) but needs further investigation, especially in the South African context.

As there is no clear policy for carers in South Africa this research would also recommend that this area is looked into by policy makers and that they develop a clear policy around the issue of family or informal carers. To develop such policies further research is needed around carers' roles, needs and experiences. This research contributes to the body of knowledge required to do this and will provide the evidence for mental health care workers to effectively provide appropriate interventions and support to persons with mental illness.

\section{References}

Bland, R., \& Foster, M. (2012). Families and mental illness: Contested perspectives and implications for practice and policy. Australian Social Work, 65(4), 517-534.

Costa Jr., P. T., Zonderman, A., B., McCrae, R., Cummings, E. M, Greene, A. L., \& Karraker, K. H. (Eds). (1991). Life-span developmental psychology: Perspectives on stress and coping. England: Hillsdale.

Crowe, A., \& Lyness, K. P. (2013). Family functioning, coping and distress in families with serious mental illness. The Family Journal, 22(2), 186-197. doi:10.1177/ 066480713513552

Diehl, M., Chui, H., Hay, E. L., Lumley, M. A., Gruhn, D., \& Labouvie-Vief, G. (2014). Change in coping and defense mechanisms across adulthood: Longitudinal findings in a European American sample. Developmental Psychology, 50(2), 634-648. doi: 10.1037/a0033619

Eisdorfer, C. (1981). Models for clinical psychopathology. New York: Medical and Scientific Books.

Fletcher, D., \& Sarkar, M. (2013). Psychological resilience: A review and critique of definitions concepts and theory. European Psychologist, 18(1), 12-23.

Flisher, A. J., Lund, C., Funk, M., Banda, M., Bhana, A., Doku, V., et al. (2007). Mental health policy development and implementation in four African countries. Journal of Health Psychology, 12, 505-516.

Greene, R. R., Galambos, C., \& Lee, Y. (2003). Resiliency theory: Theoretical and professional conceptualizations. Journal of Human Behavior in the Social Environment, 8(4), 75-91.

Greene, R. R. (2002). Resilience: Theory and research for social work practice. Washington, DC: NASW Press.

Ho, A., Collins, S. R., Davis, K., \& Doty, M. M. (2005). A look at working-age caregivers' roles, health concerns, and need for support. The commonwealth fund, Issue brief, Publication 845.

Huang, X., Sun, F., Yen, W., \& Fu, C. (2008). The coping experiences of carers who live with someone who has schizophrenia. Journal of Clinical Nursing, 817-826. doi: 10.111/j.1365-2702.2007.02130.x

Johnson, E. (2000). Differences among families coping with serious mental illness: A qualitative analysis. American Journal of Orthopsychiatry, 70(1), 126-134.

Lazarus, R. S. (1993). Coping theory and research: Past, present, and future. Psychosomatic Medicine, 55, 234-247.

Lietz, C., Langer, C. L., \& Furman, R. (2006). Establishing trustworthiness in qualitative research in social work: Implications from a study regarding spirituality. Qualitative Social Work, 5(4), 441-458.

Magliano, L., Fadden, G., Economou, M., Xavier, M., Held, T., \& Guarneri, M. (1998). Social and clinical factors influencing the choice of coping strategies in relatives of patients with schizophrenia: Results of BIOMED 1 study. Social Psychiatry and Psychiatric Epidemiology, 33, 413-419.

Romi, T., \& Melamed, S. (2007). Involving the family of patients with mental illness in treatment. Journal of Family Psychotherapy, 18(1), 11-26.

Rubin, A., \& Babbie, E. (2011). Research methods for social work (7th Ed). USA: Brooks/Cole. 
Rudnick, A. (2004). Burden of caregivers of mentally ill individuals in Israel: A family participatory study. The International Journal of Psychosocial Rehabilitation, 9(1), 147-152.

Sellmeyer, P. (2003). An exploratory study on the needs of families with a relative with Schizophrenia who is utilising services at Cape Mental Health Society (Dissertation submitted for the degree of Master of Social Science in Clinical Social Work Masters, University of Cape Town, South Africa).

Seloilwe, E. S. (2006). Experiences and demands of families with mentally ill people at home in Botswana. Journal of Nursing Scholarship, 38(3), 262-268.

Solomon, P., \& Draine, J. (1995). Subjective burden among family members of mentally ill adults. American Orthopsychiatric Association, 65(3), 419-427.

Tesch, R. (1990). Qualitative research: Analysis types and software tools. Bristol: Falmer.

Van Breda, A. D. (2001). Resilience theory: A literature review. Pretoria, South Africa: South African Military Health Service.

World Health Organization. ( 2011). World Health Statistics. Gebneva: WHO.

Williams, A. P., Peckham, A., Watkins, J., Warrick, N., Tarn, T., Rudoler, D., \& Spalding, K. (2014). Caring for caregivers: Facing up to tough challenges. Healthcare Quarterly, 17(3), 20-23.

Williams, D. R., Herman, A., Stein, D. J., Heeringa, S. G., Jackson, P. B., Moomal, H., \& Kessler, R. C. (2007). Prevalence, service use and demographic correlates of 12-month psychiatric disorders in South Africa: The South African stress and health study. Psychological Medicine. doi:10.1017/S0033291707001420.

Windle, G., \& Bennett, K. M. (2012). Caring relationships: How to promote resilience in challenging times. Social ecology of Resilience, Springer New York, 2012. 219-231. 